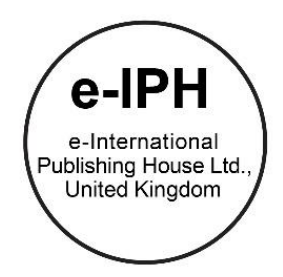

\title{
The Quality of Building as a Whole for Public Preschools at Klang Valley in Malaysia
}

\author{
Mariam Felani Shaari ${ }^{1}$, Sabarinah Sheikh Ahmad ${ }^{1}$, Izaham Shah Ismail ${ }^{2}$ \\ ${ }^{1}$ Faculty of Architecture, Planning and Surveying, ${ }^{2}$ Faculty of Education, \\ Universiti Teknologi MARA, Puncak Alam, Selangor, Malaysia \\ mariamfelani87@gmail.com sabar643@uitm.edu.my izaha740@uitm.edu.my
} Tel: +60125060875

\begin{abstract}
High-quality preschool buildings are crucial for pedagogy. This paper explores and proposes improvements to the 'building as a whole' quality of 26 Malaysian public preschools in Klang Valley. Five aspects (image and scale, circulation, common core of shared facilities, indoor environmental quality, safety, and security) were assessed with the Children's Physical Environment Rating Scale. The average 'building as a whole' quality is rated 'Good' and none were rated 'Excellent' nor 'Poor'. However, the 'common core of shared facilities' aspect was only rated 'Fair' in most preschools. Recommendations are hoped to guide stakeholders to ensure better preschools in Malaysia.
\end{abstract}

Keywords: circulation; facilities; image and scale; indoor environmental quality; safety and security.

eISSN: 2398-4287 @ 2019. The Authors. Published for AMER ABRA cE-Bs by e-International Publishing House, Ltd., UK. This is an open access article under the CC BYNC-ND license (http://creativecommons.org/licenses/by-nc-nd/4.0). Peer-review under responsibility of AMER (Association of Malaysian Environment-Behaviour Researchers), ABRA (Association of Behavioural Researchers on Asians) and cE-Bs (Centre for Environment-Behaviour Studies), Faculty of Architecture, Planning \& Surveying, Universiti Teknologi MARA, Malaysia.

DOI: https://doi.org/10.21834/ebpj.v5iSI1.2291

\subsection{Introduction}

Preschool experiences are not only limited to interactions with teachers and friends, but also with the preschool settings. Children are more sensitive to their surroundings (Ozcan, 2006). Encounters in preschool could affect the way they develop and conduct themselves later. Children who learn in poor preschool buildings are prone to many health issues - mentally (Jaakkola et al., 2013) and physically (Lee et al., 2013). Therefore, besides good educational programs, good quality preschool settings are also vital.

The importance of good quality preschool building has been advocated in many studies (Shaari \& Ahmad, 2016; Shaari et al., 2016; Loebach, 2005). However, Malaysian studies investigating the quality of preschool 'building as a whole' are limited. A study to address this will be significant in creating awareness on the importance of preschool 'building as a whole' quality in ensuring proper development of preschool children in Malaysia. Therefore, this paper attempts to extend the effort by assessing preschool 'building as a whole' aspects, namely i) Image and Scale, ii) Circulation, iii) Common Core of Shared Facilities, iv) Indoor Environmental Quality, and v) Safety and Security, in a different set of sample - MOE public preschools in Klang Valley.

\subsection{Literature Review}

The image and scale of preschool buildings are critical. They refer to the general image of the preschool from the perspective of the child (Moore, 2012). For optimum cognitive development, the preschool must appear like a typical home environment when viewed from the outside. A child needs to feel that the preschool is homey and comfortable. The impression that preschools must give to children is of warmness, appropriateness, and comfort (Malmberg et al., 2011). The confidence and sense of ownership these elements provide to children works to encourage children to explore and learn without fear and inferiority, improving their learning experiences.

eISSN: 2398-4287 ( 2019. The Authors. Published for AMER ABRA cE-Bs by e-International Publishing House, Ltd., UK. This is an open access article under the CC BYNC-ND license (http://creativecommons.org/licenses/by-nc-nd/4.0/). Peer-review under responsibility of AMER (Association of Malaysian Environment-Behaviour Researchers), ABRA (Association of Behavioural Researchers on Asians) and cE-Bs (Centre for Environment-Behaviour Studies), Faculty of Architecture, Planning \& Surveying, Universiti Teknologi MARA, Malaysia. DOI: https://doi.org/10.21834/ebpj.v5iSI1.2291 
Additionally, crowd distribution in preschool buildings also has a significant impact on the process of children's development and pedagogy. Circulation refers to the main traffic routes throughout the preschool building, both between different parts of the building and among the activity spaces used by children (in between the entrances, in useable spaces, activity areas, eating areas, and sleeping area) (Moore, 2012). Crowd distribution is crucially important because it enables children, parents, and teachers to be more organized and allows for a seamless transition between learning activities. More importantly, this helps to instill confidence and a sense of control among children. It also encourages children to explore and learn more in preschool settings (Howie et al., 2016; Wilks et al., 2015).

Aside from the quality of activity spaces and circulation, the appropriateness of common shared facilities is also crucial in complementing overall preschool building quality. The common shared facilities refer to spaces that are used for other purposes such as administration office, seating areas, staff lounge, meeting or conference room, staff or adult bathroom, laundry, kitchen, multipurpose play area, library, and storage. These aspects of the preschool building are crucial because they function to help provide a conducive environment for teachers and children (Moore, 2012).

Additionally, a comfortable and healthy indoor environment must also be available to maintain appropriate temperature, lighting, and air quality. It is a crucial component of any early childhood facility. Consequently, this is very important because it directly relates to children's physical and mental health - an important aspect that influences children's cognitive development in learning (Christian et al., 2017).

In terms of assessing the abovementioned aspects of the preschool environment, the Children's Physical Environment Rating Scale (CPERS) offers an ideal tool. Unlike other assessment tools, CPERS allows for the assessment of preschool physical aspects concerning their capability to promote cognitive development among children. Considering all the options available, this is most appropriate for the study as the Ministry of Education (MOE) requires preschools to maximize the cognitive development of preschool children (MOE, 2016).

\subsection{Method}

This paper adopts the Children's Physical Environment Rating Scale (CPERS) in the natural preschool setting. The independent variables are the selected preschools, and the dependent variables are the CPERS (Part B: Building as a whole - Subscale 2, 3, 4, 5, and 6) score for all assessed preschool building.

\subsection{Location}

In comparison, the study is distinctive as it focused on the Klang Valley region of Malaysia, which differs from previous studies held in Selangor. Both urban and non-urban areas are evaluated and included in this study.

\subsection{Sample}

This paper focuses on the Malaysian Ministry of Education (MOE) preschools. Due to cost and time constraints, preschools with five years old children were excluded. Additionally, preschools built before 2002 were also excluded. Due to undisclosed reasons, 4 out of 30 preschools were excluded. Thus, in total, 26 preschools were sampled.

\subsection{Limitation}

This study only focuses on the quality of the preschool building as a whole. Therefore, only CPERS (Part B: Building as a whole) was analyzed. Further, only one assessor was used in this study to evaluate all participating preschools. No teachers or pre-schoolers were involved in this study. Biasness may still be present in the evaluation process.

\subsection{Procedure 1: Consenting}

Firstly, approvals from five different bodies were gained to allow it to adhere to ethical procedures, enable seamless study, and avoid any conflict of interest, as shown in Figure 1.

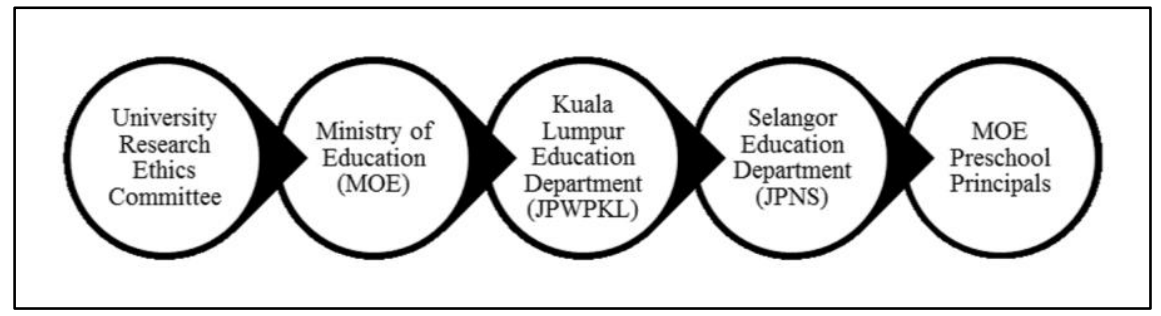

Fig. 1: Research Consenting Bodies

(Source: Author) 
Preschool principals were then requested to provide preschool background information and building floor plans upon their discretion. For preschools without floor plans, measured drawings are produced by the researcher.

\subsection{Procedure 2: Pilot Study}

The pilot study tested the overall CPERS assessment procedure. During the pilot study, the researcher gets to familiarize, foresee, and address any potential issues related to the study design.

\subsection{Procedure 3: Data Collection (Actual Assessment)}

The assessment involved walkthrough observation and scoring the 26 selected preschool buildings using the CPERS tool (Part B: Building as a whole). Every preschool building is individually assessed based on the availability of CPERS (Part B: Building as a whole) items, and how good the quality of every available item is. Depending on the difficulty, the researcher took one to two hours to complete the assessment.

\subsection{Procedure 4: Data Analysis}

Using the Statistical Package for the Social Sciences (SPSS), each raw score of CPERS (Part B: Building as a Whole) are coded and statistically analyzed. Firstly, the overall CPERS (Part B: Building as a Whole) mean score is calculated to accurately determine the average quality of the building as a whole. Then, the mean score of every CPERS (Part B: Building as a Whole) subscale is also analyzed to gauge the average quality of every preschool building as a whole aspect of the studied preschool buildings. Finally, the individual CPERS (Part B: Building as a Whole) overall, subscales and items scores are calculated for individual improvement of preschool building design.

\subsection{Findings}

The study adopted CPER5 (Part B). The five major aspects of preschool buildings, namely the Image and Scale, Circulation, Common Core of Shared Facilities, Indoor Environmental Aspects, and Safety and Security, are evaluated in each preschool to determine their overall building quality. Different scores define different quality levels as follows:

$$
\begin{aligned}
\text { i. } & 3.01-4.00=\text { Excellent } \\
\text { ii. } & 2.01-3.00=\text { Good } \\
\text { iii. } & 1.01-2.00=\text { Fair } \\
\text { iv. } & 0.00-1.00=\text { Poor }
\end{aligned}
$$

Table 1 shows the Mean score for CPERS (Part B) $(N=26)$ to be 2.1423 , indicating the average quality of 'building as a whole' of preschools is Good. The Minimum and Maximum scores are 1.76 and 2.62, respectively.

Table 1: Average CPERS (Part B: Building as a Whole) Score

\begin{tabular}{lllllll}
\hline \multirow{2}{*}{ PART B: BUILDING AS A WHOLE } & $\mathrm{N}$ & Range & Min. & Max. & Mean & Quality \\
\cline { 2 - 7 } & 26 & 0.86 & 1.76 & 2.62 & 2.14 & Good \\
\hline \multicolumn{7}{c}{ (Source: Author) }
\end{tabular}

Table 2 shows the majority of preschools $(73.08 \%)(\mathrm{N}=19)$ are Good quality; the remaining $(26.92 \%)(\mathrm{N}=7)$ are Fair quality. None has Excellent nor Poor.

Table 2: Distribution of CPERS (Part B: Building as a Whole) Scores by Quality

\begin{tabular}{lllllll}
\hline & \multicolumn{7}{l}{ Distribution of Scores by Quality } \\
\cline { 2 - 7 } PART B: BUILDING AS A WHOLE & \multirow{2}{*}{ Overall } & & Excellent & Good & Fair & Poor \\
& & $3.01-4.00$ & $2.01-3.00$ & $1.01-2.00$ & $0.00-1.00$ \\
\cline { 2 - 7 } & $\%$ & 100 & 0 & 73.08 & 26.92 & 0 \\
\hline & $\mathrm{N}$ & 26 & 0 & 19 & 7 & 0 \\
\hline
\end{tabular}

Table 3 shows CPERS (Part B) Subscales of Image and Scale, Circulation, Indoor Environmental Quality, and Safety and Security are of Good quality, with Mean scores 2.58, 2.46, 1.42, 2.02, and 2.24 respectively. However, the average quality of Common Core of Shared Facilities of the preschools is only Fair.

Table 3: Average CPERS (Part B: Building as a Whole) Subscales Scores

\begin{tabular}{lcccccl}
\hline PART B: BUILDING AS A WHOLE & N & Range & Min. & Max. & Mean & Quality \\
\hline Subscale 2: Image and Scale & 26 & 1.17 & 2.00 & 3.17 & 2.58 & Good \\
Subscale 3: Circulation & 26 & 1.34 & 1.83 & 3.17 & 2.46 & Good \\
Subscale 4: Common Core of Shared Facilities & 26 & 1.09 & 1.08 & 2.17 & 1.42 & Fair \\
Subscale 5: Indoor Environmental Quality & 26 & 1.14 & 1.57 & 2.71 & 2.02 & Good \\
Subscale 6: Safety and Security & 26 & 2.25 & 0.75 & 3.00 & 2.24 & Good \\
\hline & (Source: Author) & & & &
\end{tabular}


Table 4 shows, for Subscale 2 (Image and Scale), the majority of preschools, $92.30 \%(\mathrm{~N}=24)$, are of Good quality. The remaining $7.7 \%(\mathrm{~N}=2)$ have Excellent and Fair quality, respectively. For Subscale 3 (Circulation), only one $(3.85 \%)$ preschool has Excellent quality, $88.46 \%(\mathrm{~N}=23)$ of preschools have Good quality. The remaining $7.69 \%(\mathrm{~N}=2)$ have Fair quality. For Subscale 4 (Common Core of Shared Facilities), the majority $(96.15 \%)(\mathrm{N}=25)$ of the studied preschools have Fair quality. Only one $(3.85 \%)$ preschool is rated Good. For Subscale 5 (Indoor Environmental Quality), eleven (42.31\%) preschools are rated Good. The remaining 57.69\% ( $\mathrm{N}=$ 15) are Fair quality. For Subscale 6 (Safety and Security), fourteen (53.84\%) preschools scored Good quality. The remaining $42.31 \%$ $(\mathrm{N}=11)$ received a Fair rating. Only one $(3.85 \%)$ preschool received a Poor rating for security and safety.

Table 4: Distribution of CPERS (Part B: Building as a Whole) Subscales Scores by Quality

\begin{tabular}{|c|c|c|c|c|c|}
\hline \multirow{3}{*}{ PART B: BUILDING AS A WHOLE } & \multirow{3}{*}{ Overall } & \multicolumn{4}{|c|}{ Distribution of Scores by Quality } \\
\hline & & Excellent & Good & Fair & Poor \\
\hline & & $3.01-4.00$ & $2.01-3.00$ & $1.01-2.00$ & $0.00-1.00$ \\
\hline \multirow{2}{*}{ Subscale 2: Image and Scale } & $\% \quad 100$ & 3.85 & 92.30 & 3.85 & 0 \\
\hline & $\mathrm{N} 26$ & 1 & 24 & 1 & 0 \\
\hline \multirow{2}{*}{ Subscale 3: Circulation } & $\% \quad 100$ & 3.85 & 88.46 & 7.69 & 0 \\
\hline & $\mathrm{N} \quad 26$ & 1 & 23 & 2 & 0 \\
\hline \multirow{2}{*}{ Subscale 4: Common Core of Shared Facilities } & $\% \quad 100$ & 0 & 3.85 & 96.15 & 0 \\
\hline & $\mathrm{N} 26$ & 0 & 1 & 25 & 0 \\
\hline \multirow{2}{*}{ Subscale 5: Indoor Enviro. Quality } & $\% \quad 100$ & 0 & 42.31 & 57.69 & 0 \\
\hline & $\mathrm{N} \quad 26$ & 0 & 11 & 15 & 0 \\
\hline \multirow{2}{*}{ Subscale 6: Safety and Security } & $\% \quad 100$ & 0 & 53.84 & 42.31 & 3.85 \\
\hline & $\mathrm{N} \quad 26$ & 0 & 14 & 11 & 1 \\
\hline
\end{tabular}

\subsection{Discussion}

Although the average quality of 'building as a whole' was Good, improvements must be made, especially on the aspect of Common Core of Shared Facilities. Figure 2 demonstrates the five aspects of preschool 'building as a whole' according to the rank of improvement, determined by the Mean scores of each subscale. Consequently, from the results, we can deduce which aspect of the preschool building would need improvements the most. The item with the lowest Mean score is placed first in the improvement rank and given the highest priority as they have the lowest quality compared to other aspects being assessed.

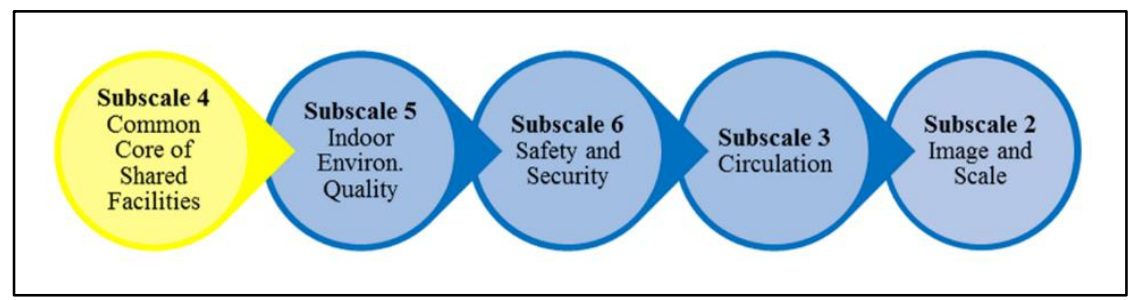

Fig. 2: Rank of Improvement for "Building as a Whole" Aspects

(Source: Author)

Firstly, the common core of shared facilities must be given the most attention to improve the preschool building as a whole. These facilities are fundamental because they function to accommodate and facilitate the main activities during formal learning sessions. As shown in Table 5, it consists of reception or waiting area, lending library, indoor multipurpose active playroom (gym), administration office, staff lounge, meeting or preparation room, adult toilets, and pantry or kitchen as well as a laundry room. They should be adequate in size, purposely built and running its specific function, and architecturally well defined. Ideally, where possible, they should also be grouped and located at the center for easy access.

Table 5: CPERS (Part B: Building as a Whole) Subscale 4 Items

\begin{tabular}{l}
\hline Subscale 4: Common Core of Shared Facilities \\
Item 4.1: Administration Office \\
Item 4.2: Reception/Waiting Area \\
Item 4.3: Staff Lounge \\
Item 4.4: Small Meeting/Preparation Room \\
Item 4.5: Adult/Staff Toilets \\
Item 4.6: Laundry Room \\
Item 4.7: Kitchen \\
Item 4.8: Indoor Multipurpose Active Playroom \\
Item 4.9: Book/Toy Lending Library \\
Item 4.10: Facilities Organisation \\
Item 4.11: Children accessibility to facilities \\
Item 4.12: Staff accessibility to facilities
\end{tabular}

(Source: Author) 
Unfortunately, on average, the assessed preschools only scored Fair quality of shared facilities. Overall, the only properly designed shared facility in most preschools is toilets and kitchens. Further, only one out of 26 preschools has a reception or waiting area appropriate for visiting parents. Only two preschools have meetings or preparation rooms for teachers. Alarmingly, no administration office, staff lounge, indoor multipurpose active playroom (gym), lending library as well as laundry rooms were found. In most preschools, teachers are only given a corner in their classrooms to store teaching material, conduct administrative work and meetings. Due to lack of staff lounges, teachers and supporting staff was found to have a break and dine either in the kitchen or at their working corners. Book and toy libraries are available but limited for in-classroom usage. Outdoor play yards equipped with large manufactured play equipment are provided to compensate for the lack of gyms. None of the provisioned adult toilets are disabled-friendly. In fact, in some preschools, adult toilets are not even provided. On the other hand, kitchens are of good quality, appropriate in size, architecturally well-defined, and purposely built for its' function.

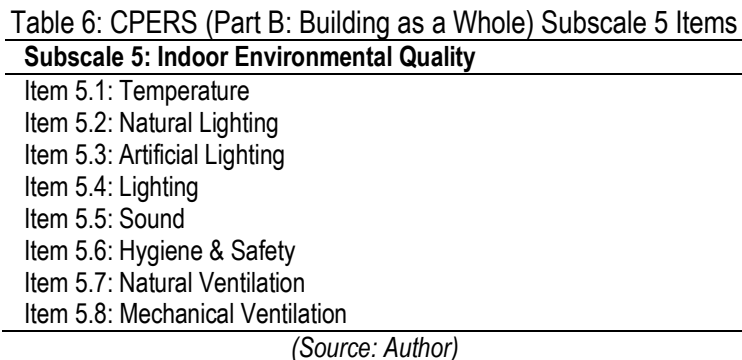

There are specific environmental characteristics that constitute Good indoor environmental quality (IEQ), as shown in Table 6. Adjustable cooling equipment such as fans, windows, and air-conditioners should be used to regulate temperature accordingly. Fans and windows are important for Malaysia's hot-humid climate. However, air-conditioners can also be used, especially on hot days. Another advantage of windows and other openings such as doors and high ceiling vents is that they allow fresh air into buildings.

Plenty of natural light, especially in children's activity spaces, is essential for visibility. Thus, appropriate placement of windows is needed to allow daylight access (Habib \& Alborzi, 2012). Harsh evening sunlight should be avoided as it could cause overall body and visual discomfort. Therefore, the placement of windows at the west facade of children activity spaces should be avoided. Alternatively, deep overhangs, window overheads, long curtains or blinds could be utilized to achieve this. On the contrary, in areas where sources of natural light are limited, adjustable artificial light could be used. They are also imperative in areas such as children's sleeping areas. However, artificial light should not replace natural light and its use must be minimal - low exposure to daylight can cause health problems (Heir \& Österbring, 2012).

Due to children's lower attention span (Cowan et al., 2006) and to minimize anxiety and distress (Krishnakumar et al., 2006), excessive noise should be kept minimal. To help dampen undesirable sound transfer, preschool indoor spaces, especially in children's activity areas, should be covered with carpets, curtains, textured wall hangings, and acoustic ceiling tiles. This goes a long way in ensuring learning activities can be maximized and that children can be isolated from harmful outdoor noise, especially from surrounding traffic. Lastly, all windows should be fitted with fly screens for hygienic purposes. Overall, it is found that the average IEQ of the studied preschools is Good. This should be commended and maintained to ensure that the preschool building itself is effective in the future.

However, there is still room for improvement. Upon examination, the study found that all preschools did not have an allocated area for sleeping or resting. Children were found to be sleeping and resting on their seats or the floor area in classrooms. It was also found that the artificial lights in the classrooms are not adjustable for sleeping purposes. This is a clear violation of the requirements for a good lighting policy for preschool buildings. Lighting must be adjustable and must be appropriate for children's activities. A "one size fits all" approach must not be used in designing environments for children as they can be detrimental for their mental and physical health. Moreover, all of the preschools have low acoustic quality - they lack features that dampen undesirable sound transfer. However, other aspects of IEQ are rated Good in all preschools.

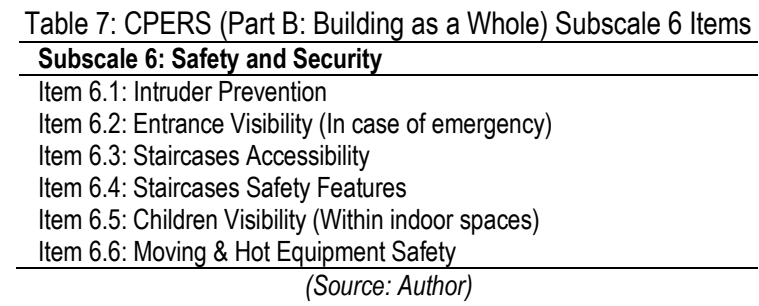

Another important aspect of preschool building is safety and security. It is primarily important to help children feel secure and ensure peace of mind among parents, teachers, and staff (Zinsser \& Zinsser, 2016). Generally, to prevent intruders, preschool entrances must be lockable, and ideally, fitted with intercom release. For shorter response times in case of emergency, at least one of those entrances should be placed within view of an office. There should be visual access from the teachers' station to most of the indoor spaces so teachers can keep an eye on children at all times. Doors with glass panels should be used especially in children's activity spaces, to 
allow visibility of children behind the doors. Self-locking staircase barriers should also be fitted to deny children unaccompanied access to staircases. Staircases and ramps should be designed with easy gradients and low-height handrails for children. Mechanical and hot equipment should be placed as high as possible or in lockable cabinets. Although the average quality of safety and security aspects of the studied preschools is rated Good, only 14 preschools possessed Good quality. Prompt improvement is required in preschools with Fair and Poor quality because safety and security is a pressing issue and should not be compromised at all cost. Furthermore, the study found that none of the preschools have intercom release. However, their gates and doors are mostly lockable. The self-locking staircase barrier is not fitted in all preschools. In terms of child suitability, the handrails were not lowered for children's scale but the steps are easy gradient for children.

Table 8: CPERS (Part B: Building as a Whole) Subscale 3 Items

\begin{tabular}{l} 
Subscale 3: Circulation \\
\hline Item 3.1: Circulation paths from preschool entrances to the main indoor activity areas \\
Item 3.2: Circulation paths visibility within activity areas \\
Item 3.3: Circulation paths interference with activity areas \\
Item 3.4: Children activity spaces visibility \\
Item 3.5: Children friendly connecting doors \\
Item 3.6: Disabled friendly circulation \\
\hline \multicolumn{1}{c}{ (Source: Author) }
\end{tabular}

Additionally, good building circulation is crucial to ensure the smooth flow of preschool programs and the distribution of foot traffic within preschool buildings. Clear, easily identifiable and well-defined routes, visible to children's activity spaces, and disabled-friendly are what defines good quality circulation in preschools. It is recommended that doors are lightweight and fitted with low handles. Among the assessed preschools, this study finds that good quality circulation is reported in most preschools. However, most of them are not disabled-friendly. Often, they are too narrow and ramps are not provided in every floor drop to accommodate wheelchair users, hindering its purpose to accommodate disabled people.

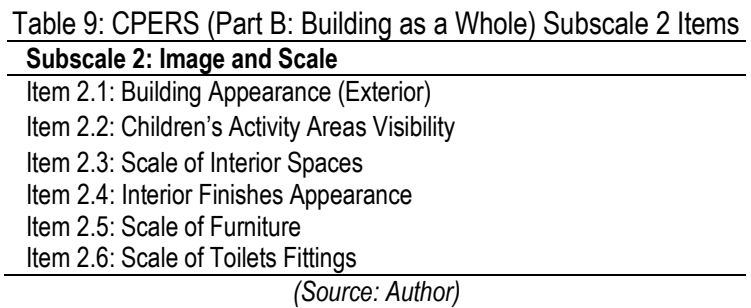

In terms of the overall image, preschool buildings should be architecturally pleasing and proportionate in size to attract and bring comfort to children (Shaari \& Ahmad, 2016). The familiar image of preschools is also important to minimize children's separation anxiety (Van der Kolk, 2017). These qualities are best represented by the image of 'home' instead of 'institution'. Single story building that is made of bricks, wood, and stones, fitted with pitched roofs and friendly entryways, painted with warm colors, equipped with child scaled openings (windows), furniture (tables, chairs, bookshelves) and fittings (sinks, water closets) are all qualities that are inviting and attractive to children. Usage of carpets, curtains and soft lighting, as well as the integration of natural elements into the preschool buildings, could further help to make the preschools a welcoming and pleasant place for learning. Furthermore, children enjoy being in a predictable environment (Carter \& Van Norman, 2010; Jackson, 2006). Therefore, the placement of low windows along the entrance path could provide children with some views of activities taking place indoors before entering the preschool. Although the studied preschools on average are rated Good for quality of image and scale, it is important to note that two out of 26 preschools are a double story. Moreover, window height is not lowered for children and floors are not adequately covered with carpets.

\subsection{Conclusion}

In conclusion, due to children's susceptibility to the surrounding, meticulous considerations are required when designing buildings for them such as preschools. The high-quality preschool building could significantly contribute to children's academic success, thus, gives them a strong foundation to be highly educated and successful citizens in the future. Preschool building as a whole, in terms of the overall preschool building image and scale, circulation, shared facilities, safety, and security, as well as environmental quality must be in excellent quality to provide children with a conducive environment for learning. The overall findings of CPERS (Part B: Building as a whole) in this study show that the studied preschool buildings' quality is not rated as Excellent. Although the average 'building as a whole' quality of the studied preschool buildings is rated as Good, there are still rooms for improvement to make them better, thus, achieve Excellent quality. It is highly suggested that the Common Core of Shared Facilities aspect (averagely rated as Fair quality) needs to be addressed first. Further improvements should also be conducted on the other 4 'building as a whole' aspects. Preschool building design guidelines and improvement recommendations discussed in this paper are useful to guide stakeholders towards providing a better-built form for preschools as well as building more preschools with Excellent quality ratings in the future. 


\section{Acknowledgments}

The authors would like to thank Professor Gary T Moore for the complimentary use of The Children's Physical Environments Rating Scale (CPERS5) in this research. Acknowledgment is also extended to the Ministry of Higher Education of Malaysia for providing the Fundamental Research Grant Scheme (FRGS), reference: 600-RMI/FRGS 5/3 (113/2015).

\section{References}

Abbas, M. Y., Othman, M., \& Rahman, P. Z. M. A. (2016). Pre-School Children's Play Behaviour Influenced by Classroom's Spatial Definitions? Asian Journal of Environment-Behaviour Studies, 1(1), 49-65.

Azhari, N. F. N., Qamaruzaman, N., Bajunid, A. F. I., \& Hassan, A. (2015). The quality of physical environment in workplace childcare centers. Procedia-Social and Behavioral Sciences, 202, 15-23.

Carter, D. R., \& Van Norman, R. K. (2010). Class-wide positive behavior support in preschool: Improving teacher implementation through consultation. Early Childhood Education Journal, 38(4), 279-288.

Christensen, D. L., Schieve, L. A., Devine, O., \& Drews-Botsch, C. (2014). Socioeconomic status, child enrichment factors, and cognitive performance among preschoolage children: results from the Follow-Up of Growth and Development Experiences study. Research in developmental disabilities, 35(7), $1789-1801$.

Cowan, N., Fristoe, N. M., Elliott, E. M., Brunner, R. P., \& Saults, J. S. (2006). Scope of attention, control of attention, and intelligence in children and adults. Memory \& cognition, 34(8), 1754-1768

Habib, F., \& Alborzi, F. (2012). The presence of light in iranian architecture: expression of values and meanings, reflecting national identity. International Conference on the Role of Cultural Heritage on The National Identity Formation, (1).

Howie, E. K., Brewer, A. E., Dowda, M., Mclver, K. L., Saunders, R. P., \& Pate, R. R. (2016). A Tale of 2 Teachers: A Preschool Physical Activity Intervention Case Study. Journal of School Health, 86(1), 23-30.

Jaakkola, M. S., Quansah, R., Hugg, T. T., Heikkinen, S. A., \& Jaakkola, J. J. (2013). Association of indoor dampness and molds with rhinitis risk: a systematic review and meta-analysis. Journal of Allergy and Clinical Immunology, 132(5), 1099-1110.

Jackson, D. (2006). Playgroups as protective environments for refugee children at risk of trauma. Australian Journal of Early Childhood, $31(2), 1$.

Krishnakumar, P., Geeta, M. G., \& Palat, R. (2006). Effectiveness of individualized education program for slow learners. Indian journal of pediatrics, 73(2), 135-137.

Lee, J. Y., So, T. Y., \& Thackray, J. (2013). A review on vitamin d deficiency treatment in pediatric patients. The Journal of Pediatric Pharmacology and Therapeutics, 18(4), $277-291$

Loebach, J. (2005). Designing learning environments for children: An affordance-based approach to providing developmentally appropriate settings. (Master dissertation, Master of Environmental Design Studies, Dalhousie University, Halifax, Nova Scotia, Canada).

Malmberg, L. E., Mwaura, P., \& Sylva, K. (2011). Effects of a preschool intervention on cognitive development among East-African preschool children: A flexibly timecoded growth model. Early Childhood Research Quarterly, 26(1), 124-133.

Ministry of Education (MOE) (2016). Kurikulum Standard Prasekolah Kebangsaan. Pendidikan Prasekolah - Dokumen Standard Kurikulum dan Pentaksiran.

Moore, G. T. (2012). Update on The Children's Physical Environments Rating Scale (CPERS5). Children Youth and Environments, 22(2), 311-312.

Ozcan, H. (2006). Healing design: A holistic approach to social interaction in pediatric intensive care units in the United States and Turkey (Doctoral dissertation, Doctoral dissertation, Texas A \& M University, USA).

Shaari, M. F., \& Ahmad, S. S. (2016). Physical Learning Environment: Impact on Children School Readiness in Malaysian Preschools. Procedia-Social and Behavioral Sciences, 222, 9-18

Shaari, M. F., Ahmad, S. S., \& Ismail, I. S. (2016). Nurturing Environmental Stewards through Preschool Physical Design. Environment-Behaviour Proceedings Journal, 1(3), 3-12.

Van der Kolk, B. A. (2017). Developmental Trauma Disorder: Toward a rational diagnosis for children with complex trauma histories. Psychiatric annals, 35(5), 401-408.

Wargocki, P., Sundell, J., Bischof, W., Brundrett, G., Fanger, P.O., Gyntelberg, F., Hanssen, S.O., Harrison, P., Pickering, A., Seppänen, O. \& Wouters, P., (2002) Ventilation and health in non-industrial indoor environments: report from a European Multidisciplinary Scientific Consensus Meeting (EUROVEN). Indoor air, 12(2), 113128.

Wilks, M., Collier-Baker, E., \& Nielsen, M. (2015). Preschool children favor copying a successful individual over an unsuccessful group. Developmental Science, 18(6), 1014-1024.

Zinsser, K. M., \& Zinsser, A. (2016). Two case studies of preschool psychosocial safety climates. Research in Human Development, 13(1), 49-64. 